\title{
Occupational Safety and Health Concerns in Logging: A Cross-Sectional Assessment in Virginia
}

\author{
Sunwook Kim ${ }^{1}$, Maury A. Nussbaum ${ }^{1, *}$ (D) , Ashley L. Schoenfisch ${ }^{2}$, Scott M. Barrett ${ }^{3}$, \\ Michael Chad Bolding ${ }^{3}$ (D) and Deborah E. Dickerson ${ }^{4}$ \\ 1 Department of Industrial \& Systems Engineering, Virginia Tech, Blacksburg, VA 24061, USA; \\ sunwook@vt.edu \\ 2 School of Nursing, Duke University, Durham, NC 27710, USA; ashley.schoenfisch@duke.edu \\ 3 Department of Forest Resources \& Environmental Conservation, Virginia Tech, Blacksburg, VA 24061, USA; \\ sbarrett@vt.edu (S.M.B.); bolding@vt.edu (M.C.B.) \\ 4 Civil and Environmental Engineering, Virginia Tech, Blacksburg, VA 24061, USA; dyoung@vt.edu \\ * Correspondence: nussbaum@vt.edu
}

Received: 29 September 2017; Accepted: 13 November 2017; Published: 15 November 2017

\begin{abstract}
Increased logging mechanization has helped improve logging safety and health, yet related safety risks and concerns are not well understood. A cross-sectional study was completed among Virginia loggers. Participants $(n=122)$ completed a self-administered questionnaire focusing on aspects of safety and health related to logging equipment. Respondents were at a high risk of workplace injuries, with reported career and 12-month injury prevalences of 51\% and $14 \%$, respectively. Further, nearly all (98\%) respondents reported experiencing musculoskeletal symptoms. Over half $(57.4 \%)$ of respondents reported symptoms related to diesel exhaust exposure in their career. Few (15.6\%), however, perceived their jobs to be dangerous. Based on the opinions and suggestions of respondents, three priority areas were identified for interventions: struck-by/against hazards, situational awareness (SA) during logging operations, and visibility hazards. To address these hazards, and to have a broader and more substantial positive impact on safety and health, we discuss the need for proactive approaches such as incorporating proximity technologies in a logging machine or personal equipment, and enhancing logging machine design to enhance safety, ergonomics, and SA.
\end{abstract}

Keywords: workplace injuries; musculoskeletal disorders; diesel exhaust exposure; mechanized logging; situational awareness

\section{Introduction}

Logging is the process of harvesting trees by which workers fell, process, and transport them for further manufacture. It is an important component of the U.S. economy, in that forest products account for $\sim 4 \%$ of the total manufacturing gross domestic product [1]. Logging is considered as one of the most dangerous occupations in the U.S., often involving heavy physical demands, nonpermanent worksites, and challenging work environments such as inclement weather, rough terrain, and being in remote or isolated locations [2]. An increase in mechanization and logger safety training have played important roles in improving logging workers' safety. These advancements have decreased adverse work-related events and injuries associated with manual tree felling and processing using a chainsaw [3-6]. However, logging machines themselves pose safety and health threats, and logging workers remain at high risk of injuries and adverse health problems. In 2015, for example, the fatality rate in the U.S. logging industry was 132.7 per 100,000 full-time equivalent (FTE) workers, the highest in any private industry [7]. Similarly, the rate of lost workday injuries was 144.1 per 100,000 FTE workers, compared to the private industry mean of 93.9 per 100,000 FTEs [8]. Common non-fatal injury 
mechanisms include contact with objects; slips, trips, and falls; and overexertion and bodily reaction, and which is consistent with processes related to the use of logging machinery. Specifically, machine operators are frequently injured while performing machine maintenance/repair $[4,9,10]$ and from falls while mounting/dismounting machinery $[4,6,10]$. Machine operators and ground logging workers also can be exposed to contact risks with moving machinery and the risk of machine rollover [6,11]. A few studies have reported that machine operators have a high prevalence of musculoskeletal disorders (MSDs), for example, in the neck, shoulder, and lower back regions [12,13], which are attributed to working postures [13] and psychological demands [14].

The use of logging machinery may have broader safety and health implications beyond work-related injuries, in that logging workers are likely exposed to machine-related diesel exhaust. Though little information is available on such exposures in the logging industry, diesel exhaust is a pervasive airborne contaminant in workplaces where diesel-powered equipment is used [15]. Diesel engine exhaust is a highly complex and variable mixture of gases, vapors, and fine particles. The amount and composition of the exhaust vary greatly, depending on factors such as fuel type, maintenance practices, workload, and exhaust system type. Vapor constituents include hydrocarbons and oxides of carbon, sulfur, and nitrogen, while particulate components consist of liquid droplets and soot particles bearing organic compounds, sulfates, metals, and other trace contaminants. The organic fraction is mainly unburned fuel and oil and can contain thousands of compounds; most notably the polycyclic aromatic hydrocarbons, which are known to be carcinogenic and genotoxic [16].

The International Agency for Research on Cancer (IARC) classifies diesel exhaust as "carcinogenic to humans (Group 1)" [17]. Large cohort and case-control studies have yielded evidence demonstrating an association between exposure to unfiltered diesel exhaust and an increased incidence of lung neoplasm [18-20]. Diesel exhaust also has been shown to be an airway irritant, triggering release of cytokines, chemokines, immunoglobulins, and oxidants [21]. It may promote expression of the immunologic response phenotype (Th2) associated with asthma and allergic disease. This immunologic evidence is consistent with epidemiologic studies associating traffic-related air pollution, and diesel exhaust, with increased prevalence of respiratory disease.

Related to mechanized logging operations, previous work provided valuable information on common injury mechanisms as described above [4,9], workers' perception of logging risks and safe work practices [22], and concerns that safety regulations and recommendations may have little impact in practice [23]. However, workplace injuries and illnesses are still an important problem in the logging industry. We thus believe that there is a current need for more detailed characterization of the circumstances surrounding loggers' injury events, their experiences with adverse outcomes related to logging equipment (e.g., MSDs and diesel exhaust exposure), and their opinions and views regarding injury prevention approaches in practice. This will enable a better understanding of the complexities of machine-related injuries and illnesses, and support the development and implementation of effective interventions that embraces the hierarchy of hazard controls in occupational injury prevention [24]. To this end, a preliminary investigation aimed to assess the prevalence of injury, symptoms related to diesel exhaust exposures, and MSD symptoms among logging workers-both overall and across worker and work-related characteristics, and determine loggers' concerns about and recommendations to improve on-the-job safety and health.

\section{Materials and Methods}

A cross-sectional study was conducted during December 2014 to August 2015 through the assistance of the Virginia Sustainable Harvesting And Research Professional (SHARP) Logger program. Note that the SHARP Logger program is a market-driven program, as opposed to a legal requirement, and requires at least one logger per crew to be trained on the principles of sustainable forestry, environmental protection, and workplace safety (visit sharplogger.vt.edu for more details). All participants completed an informed consent procedure approved by the Virginia Tech Institutional Review Board. 


\subsection{Participants}

We recruited two participant pools via convenience sampling. The first pool was from among regularly scheduled SHARP logger training classes, and the second from four different logging sites in the Mountain, Piedmont, and/or Coastal Plain regions of Virginia. For the former, we distributed a questionnaire to all attendees who indicated they worked on a logging operation during classroom-based trainings, and they were free to complete it or refuse. Logging operations differ substantially by physiographic region. However, the vast majority of all logging operations in Virginia utilize mechanized skidding and loading. In the Mountain region, operations tend to rely primarily on manual felling utilizing chainsaws while in the Piedmont and Coastal Plain, operations primarily utilize mechanized felling [25]. Questionnaires were completed at trainings in all three physiographic regions to allow for a cross-sectional assessment of operations across Virginia; however, the majority was collected in the Piedmont and Coastal Plain regions, which tend to have more mechanized operations. A total of 95 attendees completed the questionnaire. For the latter, we contacted select logging business owners for study solicitation and site visit approval. Four different logging sites were visited, at which the questionnaire was distributed. A total of 27 logging workers completed the questionnaire on-site.

\subsection{Questionnaire}

The self-administered questionnaire was developed based on earlier studies on mechanized logging operations [9,13], symptoms associated with diesel exhaust exposure [26,27], and existing validated instruments such as the standardized Nordic questionnaires for musculoskeletal symptoms [28]. Specifically, the questionnaire consisted of 23 yes/no, categorical, and open-ended questions covering: (1) personal and job characteristics (i.e., time in the industry, primary job, daily machine operation time); (2) perceived safety, safety training, and personal protective equipment (PPE) usage; (3) work-related injuries (e.g., circumstance surrounding injury events, post-injury care, reporting); (4) symptoms related to diesel exhaust exposure (e.g., eye irritation, wheezing); (5) MSD symptoms (i.e., pain, stiffness, spasm, aching, burning, tingling, or numbness); and (6) perceived safety concerns (machine operators and workers on the ground) and recommendations for improved safety and health. Note that the questionnaire is provided in online Supplemental Material.

\subsection{Data Analysis}

The distributions of close-ended questionnaire responses were summarized using means and standard deviations, or proportions, as relevant. Differences in participant characteristics between physiographic regions in Virginia, USA (i.e., Coastal Plain, Piedmont, Mountains) were examined using Kruskal-Wallis one-way analyses of variance or Pearson's Chi-squared tests as appropriate. Participants' career and 12-month prevalence of self-reported health outcomes (i.e., work-related injuries, symptoms related to diesel exhaust exposure, and MSD symptoms) were examined overall and across employment duration, primary job, daily machine operation, physiographic region, perceived safety of the job, and attitude toward PPE use. Using log-binomial regression, prevalence ratios and $95 \%$ confidence intervals (CIs) were calculated to explore relative differences in career and 12-month prevalence of the study outcomes across worker and job characteristics. Open-ended question responses were reviewed and discussed by investigators to identify naturally emerging themes, based on which the responses were sorted into content categories and sub-categories. The frequency and proportion of responses within each category are reported. All statistical analyses were performed using R statistical software [29]. 


\section{Results}

\subsection{Characteristics of Questionnaire Respondents}

All $(n=122)$ of the questionnaire respondents were male, and responses are summarized in Table 1. Participants represented each of the physiographic regions of Virginia (Coastal Plain 48.4\%, Piedmont 34.4\%, Mountains 17.2\%), and no significant differences between physiographic regions were observed in demographic and job characteristics, perception of job safety, or PPE use, though the distribution of primary job categories did differ between regions $(p=0.008)$. More owners completed the questionnaire in the Mountains region (Coastal Plain 16.7\%, Piedmont 31.4\%, Mountains 55.6\%). Overall, participants had an average of 17.3 years of experience in logging and 8 hours of daily machine operation duration, and half $(50.8 \%)$ had a primary job operating a machine. Machine types reported included loader, feller-buncher, skidder, and truck. Relatively few respondents (15.6\%) considered their job to be very/extremely dangerous and $45.9 \%$ considered it to be moderately dangerous, while a majority (68.9\%) reported that using PPE is very/extremely important. All respondents received safety training from multiple sources, with more common sources being SHARP logger classes (48.4\%) and on-the-job/safety training from co-workers, crew foremen, and/or owners $(46.0 \%)$.

\subsection{Prevalence of Work-Related Injury, Symptoms Related to Diesel Exhaust Exposure, and MSD Symptoms}

The career prevalence of logging work-related injury among participants was 50.8\%, and it increased with increasing years of experience (Table 1). The 12-month prevalence was $13.9 \%$. Seventeen respondents experienced injuries in the prior year, and common injury causes were chainsaw use $(41.2 \%)$, a slip/fall from a machine $(23.5 \%)$, or being struck by a tree or machine $(17.6 \%)$. Commonly affected body parts were the lower (34.5\%) and upper (34.5\%) extremities. A total of $10(58.8 \%)$ injuries in the prior year resulted in missed work (range: 0.5 days to 8 months). A total of $70.1 \%(n=12)$ of injuries in the prior year required medical care beyond first aid, and $41.2 \%(n=7)$ were reported as a WC claim. In addition, over half (57.4\%) of respondents reported symptoms related to diesel exhaust exposure in their career, and the symptom prevalence was not associated with the worker or job characteristics we considered.

Table 1. Career prevalence, prevalence ratios (PR) and 95\% confidence intervals (CI) of work-related injury and symptoms related to diesel exhaust exposure among a sample of loggers in Virginia, USA.

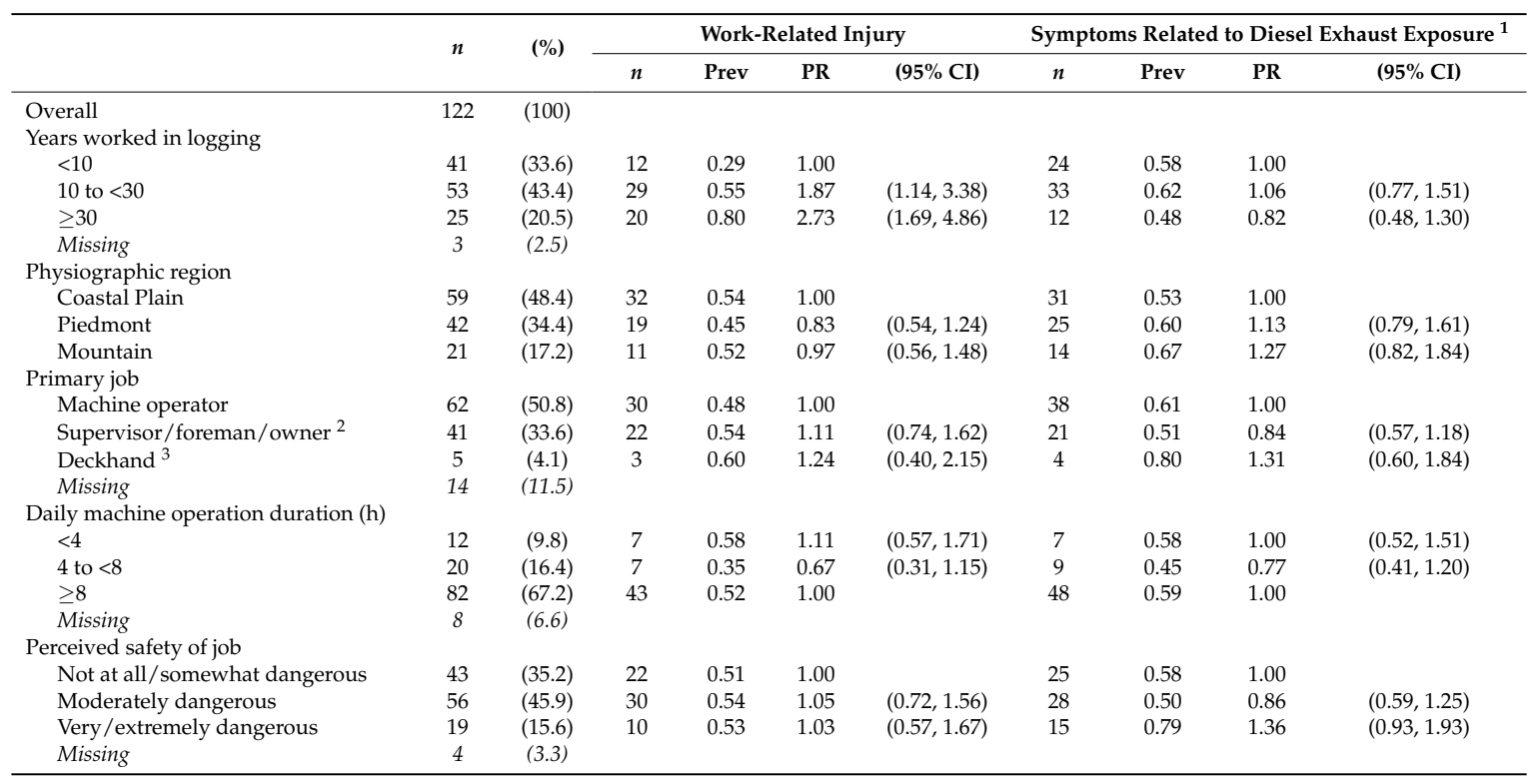


Table 1. Cont

\begin{tabular}{|c|c|c|c|c|c|c|c|c|c|c|}
\hline & \multirow{2}{*}{$n$} & \multirow{2}{*}{$(\%)$} & \multicolumn{4}{|c|}{ Work-Related Injury } & \multicolumn{4}{|c|}{ Symptoms Related to Diesel Exhaust Exposure ${ }^{1}$} \\
\hline & & & $n$ & Prev & PR & $(95 \% \mathrm{CI})$ & $n$ & Prev & PR & $(95 \% \mathrm{CI})$ \\
\hline \multicolumn{11}{|l|}{ Attitude toward using PPE } \\
\hline Not at all important & 11 & $(9.0)$ & 6 & 0.55 & 1.15 & $(0.54,1.85)$ & 5 & 0.45 & 0.75 & $(0.31,1.27)$ \\
\hline Very/extremely important & 84 & (68.9) & 40 & 0.48 & 1 & & 51 & 0.61 & 1 & \\
\hline Missing & 1 & $(0.8)$ & & & & & & & & \\
\hline
\end{tabular}

${ }^{1}$ Experience of eye/mouth irritation and/or unpleasant smell when operating a machine or while working near a machine; ${ }^{2}$ All owners reported that they normally or at least occasionally worked in the woods and operated equipment (i.e., work alongside crew members); ${ }^{3}$ Based on our experience and observation, the deckhand helped with moving trailers on the deck, trimming loads (using a pole saw to cut any branches or vines sticking out of the side of the load), and with maintenance in addition to operating a machine.

Nearly all (98\%) respondents reported experiencing MSD symptoms in at least one body region in the past 12 months, and $93 \%$ had MSD symptoms in more than one body region. The 12-month prevalence of MSD symptoms in each of nine body regions is summarized in Table 2 . The body region most commonly affected was the lower back $(49.2 \%)$, followed by the knee (37.7\%). About one-fifth $(18.5 \%)$ of those with MSD symptoms indicated that they changed their work methods due to their MSD symptoms. Further, 10 respondents (8.4\%) missed work as a result of their MSD symptoms, and the same number had considered changing jobs.

Table 2. Crude (i.e., unadjusted) 12-month prevalence of MSD symptoms by body region.

\begin{tabular}{|c|c|c|c|c|c|c|c|c|c|c|}
\hline & $n$ & $\begin{array}{l}\text { Neck } \\
(\%)\end{array}$ & $\begin{array}{l}\text { Shoulder } \\
\text { (\%) }\end{array}$ & $\begin{array}{c}\text { Elbow } \\
(\%)\end{array}$ & $\begin{array}{l}\text { Wrist } \\
(\%)\end{array}$ & $\begin{array}{c}\text { Upper Back } \\
(\%)\end{array}$ & $\begin{array}{c}\text { Lower Back } \\
(\%)\end{array}$ & $\begin{array}{l}\text { Hip } \\
(\%)\end{array}$ & $\begin{array}{c}\text { Knee } \\
(\%)\end{array}$ & $\begin{array}{l}\text { Foot } \\
(\%)\end{array}$ \\
\hline \multicolumn{10}{|l|}{ Experience (years) } & 21.3 \\
\hline 10 to $<30$ & 53 & 26.4 & 28.3 & 18.9 & 28.3 & 86.8 & 52.8 & 7.6 & 34.0 & 13.2 \\
\hline$\geq 30$ & 25 & 28.0 & 48.0 & 8.0 & 24.0 & 12.0 & 44.0 & 12.0 & 36.0 & 20.0 \\
\hline \multicolumn{11}{|l|}{ Primary job } \\
\hline Deckhand & 5 & 20.0 & 40.0 & 40.0 & 40.0 & 0.0 & 40.0 & 20.0 & 20.0 & 40.0 \\
\hline \multicolumn{11}{|l|}{ Daily machine operation duration ( $h$ ) } \\
\hline$<4$ & 12 & 8.3 & 25.0 & 0.0 & 16.7 & 0.0 & 41.7 & 16.7 & 8.3 & 16.7 \\
\hline 4 to $<8$ & 20 & 25.0 & 35.0 & 15.0 & 30.0 & 80.0 & 45.0 & 20.0 & 30.0 & 25.0 \\
\hline$\geq 8$ & 82 & 32.9 & 37.8 & 20.7 & 31.7 & 81.7 & 51.2 & 9.8 & 46.3 & 23.2 \\
\hline
\end{tabular}

\subsection{Perceived Safety Concerns and Recommendations}

About half $(48.0 \%)$ of participants' perceived safety risks in logging operations were related to struck by/against hazards, often related to chainsaw operation and felling/delimbing/topping activities (Table 3). One fourth (26\%) were related to poor situational awareness due to inattention/distraction/work speed, machine operation, and communication. When asked "when you are a machine operator, what do you see as the biggest safety risk for workers on ground?", participants indicated that the biggest safety risks involve poor situational awareness (40.2\%) and visibility hazards ( $34.5 \%$ ) (Table 4$)$. To improve safety on their job sites or in logging operations in general, many suggested a need for improving situational awareness, more safety training and education, and use of personal protective equipment (PPE) (Table 5). 
Table 3. Summary of responses (total $=77$ responses, from 77 individuals who responded to this open-end question) regarding the biggest safety risks perceived during logging operations. Note that $n$ in the table is the number of responses obtained.

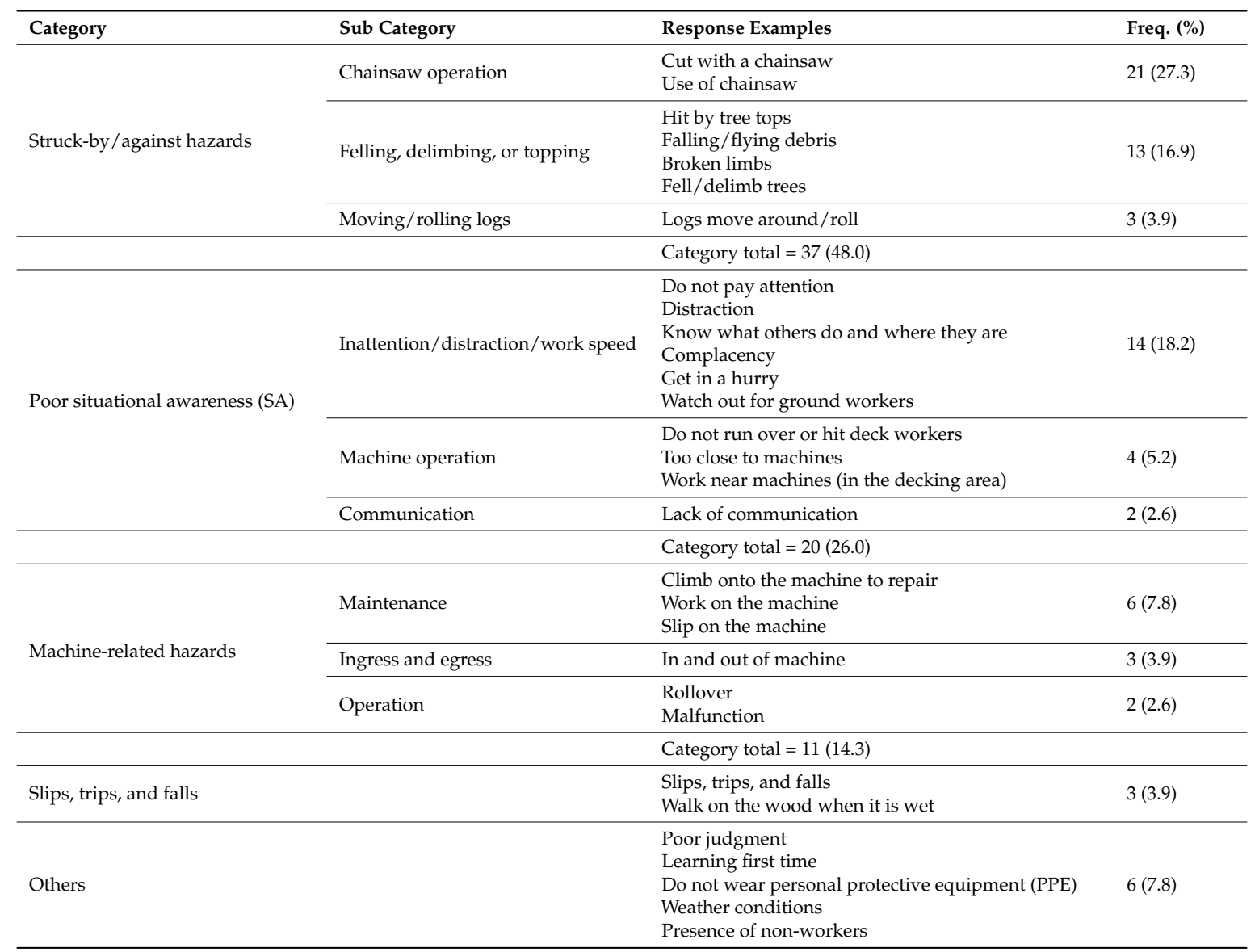

Table 4. Summary of responses (total $=87$, responses from 86 individuals who responded to this open-end question) regarding the biggest safety risks that machine operators perceive for workers on the ground. Note one participant provided two responses, and that $n$ in the table is the number of responses obtained.

\begin{tabular}{|c|c|c|c|}
\hline Category & Sub Category & Response Examples & Freq. (\%) \\
\hline \multirow{4}{*}{ Poor situational awareness (SA) } & Inattention/distraction & $\begin{array}{l}\text { Do not pay attention } \\
\text { Do not stay focused } \\
\text { Do not watch out for machines } \\
\text { Complacency }\end{array}$ & $17(19.5)$ \\
\hline & Proximity to hazards (e.g., machine) & $\begin{array}{l}\text { Too close to machines } \\
\text { Keep safe distance from machines }\end{array}$ & $15(17.2)$ \\
\hline & Communication & Do not make an operator see you & $3(3.4)$ \\
\hline & & Category total $=35(40.2)$ & \\
\hline Visibility hazards & & $\begin{array}{l}\text { Visible } \\
\text { Do not stay in the blind spot of an operator } \\
\text { Stay in the sight of an operator }\end{array}$ & $30(34.5)$ \\
\hline \multirow{4}{*}{ Struck-by/against hazards } & Felling, delimbing, or topping & $\begin{array}{l}\text { Falling/flying debris/limbs } \\
\text { Fell trees }\end{array}$ & $14(16.1)$ \\
\hline & Machine-related (Operation) & $\begin{array}{l}\text { Lose control of logs in the log grapple } \\
\text { Knock logs (or other objects) onto ground workers }\end{array}$ & $5(5.7)$ \\
\hline & Moving/rolling objects & Rolling objects & $1(1.1)$ \\
\hline & & Category total $=20(23.0)$ & \\
\hline Others & & $\begin{array}{l}\text { Backup alarms are too quiet } \\
\text { Common sense }\end{array}$ & $2(2.3)$ \\
\hline
\end{tabular}


Table 5. Summary of suggestions (total $=92$ responses, from 81 individuals who responded to this open-end question) offered for safety improvements. Note that $n$ in the table is the number of responses obtained.

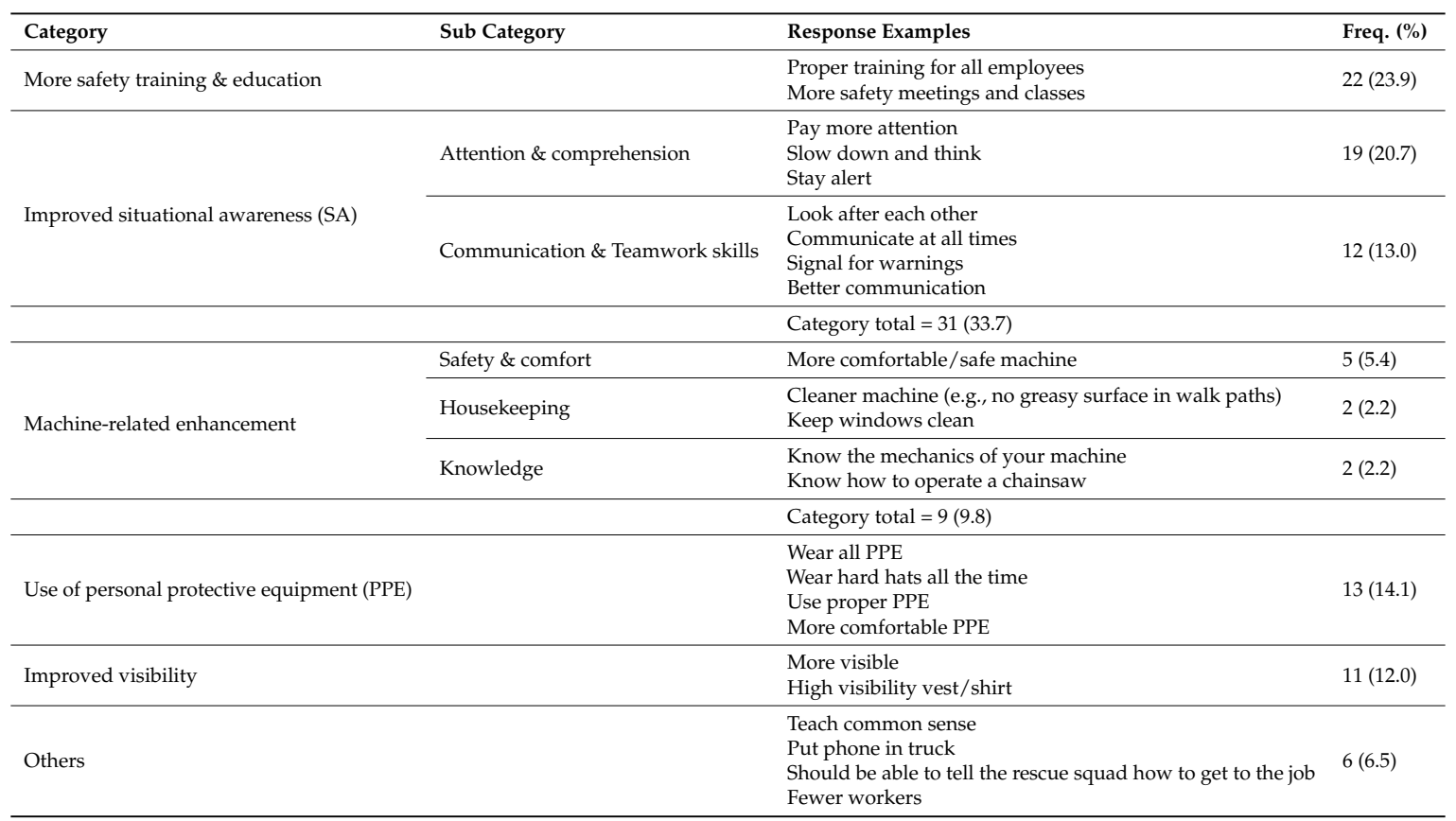

\section{Discussion}

This cross-sectional study examined a sample of Virginia loggers to investigate the prevalence of workplace injuries, MSD symptoms, and symptoms related to diesel exhaust exposure, and to help understand their safety concerns and opinions with a particular focus on logging equipment.

\subsection{Workplace Injuries and MSDs}

Loggers included here were at a high risk of workplace injuries, with reported career and 12-month prevalences of $51 \%$ and $14 \%$, respectively. The latter is, however, lower than earlier reports for forestry workers, including a 12-month injury prevalence of $34 \%$ for all forestry tasks/jobs (e.g., chainsaw operators, silviculturists) in New Zealand [30] and a 12-month prevalence (including work-related illnesses) of $30 \%$ for the farming, forestry, and fishing industry [31]. This discrepancy may be due to a focus on more general worker populations (i.e., not limited to loggers in predominantly mechanized logging operations) in these two earlier studies. We found that work-related injury prevalence (Table 1), but not MSD symptom prevalence (Table 2), was associated with years of experience. Nieuwenhuis et al. [9] found no significant association between years of experience and MSD prevalence for forestry workers in Ireland, and Lynch et al. [13] reported that age was not significantly associated with back pain but positively associated with neck pains for machine operations in the U.S. Southern region.

Nearly all respondents experienced MSD symptoms in at least one body region over the prior 12 months. A substantial fraction of respondents (18.5\%) reported that they had changed their work practice as a result of MSD symptoms, and $\sim 8 \%$ further indicated that they were considering changing jobs. Interestingly, knee MSD symptoms appeared to have a positive relationship with daily machine operation duration (Table 2). This may suggest operating a machine also contributes to knee MSDs, though a previous report noted that many of knee and foot injuries resulted from being struck by/against an object [6]. Additionally, the body region most commonly affected was the lower back $(49.2 \%)$, followed by the knee $(37.7 \%)$. These values are lower than earlier reports (12-month prevalence) of $74.3 \%$ (lower back pain) for machine operators in the US Southern region [13], and $84.6 \%$ (lower back) and $61.5 \%$ (knee) for Greek forestry workers [32]. Such a differential may have 
resulted from the use of a different questionnaire instrument for assessing symptoms in the former study (vs. the standardized Nordic questionnaires used here), and the fact that the study population in the latter mainly included workers who performed both manual and mechanized timber-cutting harvesting in a steep mountain forest terrain.

\subsection{Symptoms Related to Diesel Exhaust Exposure}

The findings of the questionnaire coupled with those of the fine particulate sampling suggest the need for additional research on the possible association of diesel exhaust exposure and adverse health effects among these workers. More than half of the study respondents reported having work-related eye/mouth irritation and/or unpleasant smells when operating a machine or when working near a machine. These irritant effects are commonly observed following exposure to diesel exhaust [26,27]. Though not statistically significant, deckhand machine operators exhibited a higher prevalence of such symptoms $[\mathrm{PR}=1.31(0.60,1.84)]$. Serving as a deckhand means working on the ground, which likely accounts for the observation that deckhand machine operators experienced a higher prevalence/level of diesel exhaust exposure symptoms. Working on the ground may increase the likelihood of exposure to diesel exhaust and other air pollutants.

Earlier studies demonstrated adverse health effects of diesel exhaust, including allergic reaction, asthma [19], chronic obstructive pulmonary disease [33], and lung cancer [20]. Considering this evidence, and our findings, there is a need for larger, more systematic investigations to quantify and characterize exposure to fine particulate $\left(\mathrm{PM}_{2.5}\right)$ fraction of diesel exhaust as an indicator of total exhaust exposure during logging equipment use and for different machine/job types (e.g., feller-buncher, deckhand), and with respect to work and maintenance practices (e.g., closing cabin windows, replacing air filters). For those working in a logging machine, vehicle cabin air filters can effectively reduce diesel exhaust particles and the symptoms induced by diesel exhaust, albeit depending on filter types [26]. However, additional attention is needed to address control of diesel exhaust exposure for ground workers.

\subsection{Safety Concerns and Opinions of Loggers}

Based on respondents' perceptions of the more common safety risks (Tables 4 and 5), as well as quantitative results regarding work-related injury prevalence, a priority of interventions may be given to address: (1) struck-by/against hazards; (2) maintaining situational awareness (SA) during logging operations (especially since such operation often require long work shifts and are quite repetitive); and (3) visibility hazards. Respondents' concerns about struck-by/against hazards are consistent with the fact that these hazards are a major source of nonfatal and fatal work-related injuries among loggers [7,34-36]. Even on these mechanized operations, participants' responses suggest chainsaw operation and felling/delimbing/topping remained frequent concerns on logging sites. Machine related struck-by events were of concern as well. Given that failures to detect and recognize hazards can be viewed as a SA problem [37], concerns regarding SA and visibility suggest a high demand on both machine operators and ground workers to process the information they perceive, and thereby to identify and prioritize hazards while maintaining good SA of the machine being operated and their surroundings (e.g., ground worker locations, physical work environments, movement of nearby machines). In addition to these three priority areas, our results support the need for efforts to understand and address loggers' musculoskeletal disorders and symptoms related to diesel exhaust exposure.

Improved SA, more training and education, and use of PPE were frequently suggested as ways to address existing logger safety risks (Table 5). With training and experience, workers can develop an efficient strategy to direct and distribute their attention to detect and recognize important stimuli [38]. However, a minimal level of SA can be determined by the attentional capacity of an individual [38], and such capacity is affected by many factors such as, for example, workload, time pressure, fatigue, and sleep deprivation $[39,40]$. In the case of safety training, though training can positively affect 
worker behaviors, large positive impacts on the incidence of adverse work-related outcomes are not generally expected from training alone [41,42]. The West Virginia Loggers' Safety Initiative (LSI) program evaluated the effectiveness of training over a 4-year period, and found no strong evidence of injury reduction [43], though loggers had increased safety knowledge [44]. Similar outcomes were reported for a multi-year video-based safety training intervention program for West Virginia loggers [45]. Interestingly, Conway et al. [22] reported that one important risk factor is human error, due to complacency, inattention, and/or underestimation of risks, and suggested that such error can be partially related to the repetitiveness of logging jobs and individual worker's motivation to work safely.

Overall, it appears that there is a need for interventions that are based not just on the behavioral changes and cognitive performance of an individual worker (e.g., training, experience). Well-designed alarms / warnings and displays can aid in efficiently allocating attention, potentially facilitating good SA $[38,40]$. The safety of logging machines may be intrinsically enhanced by incorporating proactive proximity warning technologies [46], and evaluating the cab design and human-machine interface of a machine for visibility and better SA during the development phases [40,47]. Further, and given the identified machine-related hazards and provided suggestions, logging machine design may benefit from user-centered and/or simulation-based design methods to enhance the safety and ergonomics, in order to achieve better operating postures [48,49], enhanced maintainability [50], and easier ingress and egress [51,52]. Similarly, proactive technologies to mitigate visibility hazards can be used among ground workers (e.g., a radio-frequency identification tag attached to a hard hat or vest as part of a proximity detection system [53]), in addition to the respondents' suggestions such as better communications (e.g., hand signal, two-way radio) and high-visibility vest use. In addition to efforts to address hazards unique to mechanized operations, approaches to prevent injuries related to chainsaw operation and felling/delimbing/topping should remain.

Limitations of the current study should be acknowledged. First, the study had a small sample size and used a convenience sampling from workers operating a variety of equipment on logging operations in different physiographic regions of Virginia. It is unknown regarding the extent to which our results will generalize to other states and countries. Our study, though, was not about specific logging practices and methods used in the test regions, but instead about logger safety and health associated with common logging operations. Second, injury and health outcome data were self-reported, which may be influenced by recall bias. To what extent such bias may have occurred is difficult to ascertain. In addition, and specific to the questions about diesel exhaust exposure, responses may have been influenced by smoking status or other preexisting health conditions.

\section{Conclusions}

In this cross-sectional study, using a sample of Virginia loggers, work-related injuries and MSDs were found to be quite prevalent among loggers, though many of these workers perceived their jobs as being only moderately dangerous or less so. Based on the current results, three priority areas were identified for interventions: struck-by/against hazards, situational awareness during logging operations, and visibility hazards. Though on-site training/educational materials (e.g., hand signals, high visibility vest and other PPE use) may be useful to address these hazards, we suggest a current need for proactive approaches, such as incorporating proactive proximity technologies in a logging machine or personal equipment, and enhancing logging machine design for better safety, ergonomics, and SA. We believe that proactive approaches are essential to achieve a broader and more substantial positive impact on safety and health among both machine operators and ground workers. In addition, our results are supportive of future efforts to improve awareness of the risk of musculoskeletal and diesel exhaust exposures and understand such exposures among logging workers.

Supplementary Materials: The following are available online at www.mdpi.com/1999-4907/8/11/440/s1. 
Acknowledgments: The authors thank Will Saulnier and Andrew Vinson for their assistance in data collection. This work was supported through the Johns Hopkins NIOSH Education and Research Center for Occupational Safety and Health, Pilot Project Research Training Award (T42 OH0008428). The contents of this paper are solely the responsibility of the authors and do not necessarily represent the official views of the National Institute for Occupational Safety and Health.

Author Contributions: Study design and questionnaire development-All; Data collection-Michael Chad Bolding, Deborah E. Dickerson, Sunwook Kim, and Scott M. Barrett; Data analysis and interpretation-Sunwook Kim, Maury A. Nussbaum, Deborah E. Dickerson, and Ashley L. Schoenfisch; Drafting and revising the manuscript-All.

Conflicts of Interest: The authors declare no conflict of interest.

\section{References}

1. American Forest \& Paper Association Economic Impact. Available online: http://www.afandpa.org/ourindustry/economic-impact (accessed on 4 April 2016).

2. National Institute for Occupational Safety and Health Logging Safety. Available online: http://www.cdc. gov/niosh/topics/logging/ (accessed on 18 April 2016).

3. Albizu-Urionabarrenetxea, P.; Tolosana-Esteban, E.; Roman-Jordan, E. Safety and health in forest harvesting operations. Diagnosis and preventive actions. A review. For. Syst. 2013, 22, 392-399. [CrossRef]

4. Roberts, T.; Shaffer, R.M.; Bush, R.J. Injuries on mechanized logging operations in the southeastern United States in 2001. For. Prod. J. 2005, 55, 86-89.

5. Shaffer, B.; Roberts, T. Logging Injuries Continue Downward Trend; Forest Operations Review: Rockville, MD, USA, 2003; pp. 21-22.

6. Lefort, A.J., Jr.; de Hoop, C.F.; Pine, J.C. Characteristics of injuries in the logging industry of Louisiana, USA: 1986 to 1998. Int. J. For. Eng. 2003, 14, 75-89.

7. Bureau of Labor Statistics Census of Fatal Occupational Injuries (CFOI) - Current and Revised Data. Available online: https: / / www.bls.gov/iif/oshcfoil.htm\#2015 (accessed on 8 September 2017).

8. Bureau of Labor Statistics. TABLE R5. Incidence Rates for Nonfatal Occupational Injuries and Illnesses Involving Days Away from Work per 10,000 Full-Time Workers by Industry and Selected Natures of Injury or Illness, Private Industry, 2015. Available online: https://www.bls.gov/iif/oshwc/osh/case/ostb4757.pdf (accessed on 4 April 2016).

9. Nieuwenhuis, M.; Lyons, M. Health and safety issues and perceptions of forest harvesting contractors in Ireland. Int. J. For. Eng. 2002, 13, 69-76.

10. Shaffer, R.M.; Milburn, J.S. Injuries on feller-buncher/grapple skidder logging operations in the Southeastern United States. For. Prod. J. 1999, 49, 24-26.

11. Myers, J.R.; Fosbroke, D.E. Logging fatalities in the United States by region, cause of death, and other factors-1980 through 1988. J. Saf. Res. 1994, 25, 97-105. [CrossRef]

12. Axelsson, S.Å.; Pontén, B. New ergonomic problems in mechanized logging operations. Int. J. Ind. Ergon. 1990, 5, 267-273. [CrossRef]

13. Lynch, S.M.; Smidt, M.F.; Merrill, P.D.; Sesek, R.F. Incidence of MSDs and Neck and Back Pain among Logging Machine Operators in the Southern U.S. J. Agric. Saf. Health 2014, 20, 211-218. [PubMed]

14. Hagen, K.B.; Magnus, P.; Vetlesen, K. Neck/shoulder and low-back disorders in the forestry industry: Relationship to work tasks and perceived psychosocial job stress. Ergonomics 1998, 41, 1510-1518. [CrossRef] [PubMed]

15. U.S. Department of Health and Human Service. National Institute for Occupational Safety and Health Current Intelligence Bulletin 50; U.S. Department of Health and Human Service: Cincinnati, OH, USA, 1988.

16. Crump, K.; Van Landingham, C. Evaluation of an exposure assessment used in epidemiological studies of diesel exhaust and lung cancer in underground mines. Crit. Rev. Toxicol. 2012, 42, 599-612. [CrossRef] [PubMed]

17. Straif, K.; Benbrahim-Tallaa, L.; Baan, R.; Grosse, Y.; Secretan, B.; Ghissassi, E.F.; Bouvard, V.; Guha, N.; Freeman, C.; Galichet, L.; et al. WHO International Agency for Research on Cancer Monograph Working Group A review of human carcinogens-Part C: Metals, arsenic, dusts, and fibres. Lancet Oncol. 2009, 10, 453-454. [CrossRef]

18. Boffetta, P.; Harris, R.E.; Wynder, E.L. Case-control study on occupational exposure to diesel exhaust and lung cancer risk. Am. J. Ind. Med. 1990, 17, 577-591. [PubMed] 
19. Attfield, M.D.; Schleiff, P.L.; Lubin, J.H.; Blair, A.; Stewart, P.A.; Vermeulen, R.; Coble, J.B.; Silverman, D.T. The Diesel Exhaust in Miners study: A cohort mortality study with emphasis on lung cancer. JNCI 2012, 104, 869-883. [CrossRef] [PubMed]

20. Bhatia, R.; Lopipero, P.; Smith, A.H. Diesel Exhaust Exposure and Lung Cancer. Epidemiology 1998, 9, 84-91. [CrossRef] [PubMed]

21. Pandya, R.J.; Solomon, G.; Kinner, A.; Balmes, J.R. Diesel exhaust and asthma: Hypotheses and molecular mechanisms of action. Environ. Health Perspect. 2002, 110, 103-112. [CrossRef] [PubMed]

22. Conway, S.H.; Pompeii, L.A.; Casanova, V.; Douphrate, D.I. A qualitative assessment of safe work practices in logging in the southern United States. Am. J. Ind. Med. 2016, 60, 58-68. [CrossRef] [PubMed]

23. Bordas, R.M.; Davis, G.A.; Hopkins, B.L.; Thomas, R.E.; Rummer, R.B. Documentation of hazards and safety perceptions for mechanized logging operations in East Central Alabama. J. Agric. Saf. Health 2001, 7, 113-123. [CrossRef] [PubMed]

24. Lipscomb, H.J.; Schoenfisch, A.L. Reflections on Occupational Injury Control. Saf. Sci. Monit. 2014, 18, 1-8.

25. Bolding, M.C.; Barrett, S.M.; Munsell, J.F.; Groover, M.C. Characteristics of Virginia's logging businesses in a changing timber market. For. Prod. J. 2010, 60, 86-93. [CrossRef]

26. Rudell, B.; Wass, U.; Hörstedt, P.; Levin, J.O.; Lindahl, R.; Rannug, U.; Sunesson, A.L.; Ostberg, Y.; Sandström, T. Efficiency of automotive cabin air filters to reduce acute health effects of diesel exhaust in human subjects. Occup. Environ. Med. 1999, 56, 222-231. [CrossRef] [PubMed]

27. Laumbach, R.J.; Kipen, H.M.; Kelly-McNeil, K.; Zhang, J.; Zhang, L.; Lioy, P.J.; Ohman-Strickland, P.; Gong, J.; Kusnecov, A.; Fiedler, N. Sickness Response Symptoms among Healthy Volunteers after Controlled Exposures to Diesel Exhaust and Psychological Stress. Environ. Health Perspect. 2011, 119, 945-950. [CrossRef] [PubMed]

28. Kuorinka, I.; Jonsson, B.; Kilbom, A.; Vinterberg, H.; Biering-Sørensen, F.; Andersson, G.; Jørgensen, K. Standardised Nordic questionnaires for the analysis of musculoskeletal symptoms. Appl. Ergon. 1987, 18, 233-237. [CrossRef]

29. Core Team R. A Language and Environment for Statistical Computing; R Foundation for Statistical Computing: Vienna, Austria, 2015.

30. Lilley, R.; Feyer, A.-M.; Kirk, P.; Gander, P. A survey of forest workers in New Zealand. Do hours of work, rest, and recovery play a role in accidents and injury? J. Saf. Res. 2002, 33, 53-71. [CrossRef]

31. Fan, Z.J.; Bonauto, D.K.; Foley, M.P.; Silverstein, B.A. Underreporting of Work-Related Injury or Illness to Workers' Compensation: Individual and Industry Factors. J. Occup. Environ. Med. 2006, 48, 914-922. [CrossRef] [PubMed]

32. Gallis, C. Work-related prevalence of musculoskeletal symptoms among Greek forest workers. J. Ind. Ergon. 2006, 36, 731-736. [CrossRef]

33. Sehra, G.; Barnes, P.; Rogers, D.; Donnelly, L. Effect of diesel exhaust particles (DEP) on monocyte-derived macrophage (MDM) mediator release and phagocytosis in chronic obstructive pulmonary disease (COPD). Eur. Respir. J. 2013, 42, 618.

34. Bureau of Labor Statistics Injuries, Illnesses, and Fatalities. Available online: http://www.bls.gov/iif/osh_ nwrl.htm (accessed on 23 August 2017).

35. Roberts, E.T.; Bolding, M.C. A Ten Year Analysis of Timber Harvesting Injuries in the Southeastern United States; Master of Forestry Paper; Virginia Tech: Blacksburg, VA, USA, 2012; pp. 1-28.

36. Lagerstrom, E.; Magzamen, S.; Rosecrance, J. A mixed-methods analysis of logging injuries in Montana and Idaho. Am. J. Ind. Med. 2017, 25, 1-11. [CrossRef] [PubMed]

37. Kaber, D.B.; Endsley, M.R. The effects of level of automation and adaptive automation on human performance, situation awareness and workload in a dynamic control task. Theor. Issues Ergon. Sci. 2007, 5, 113-153. [CrossRef]

38. Durso, F.T.; Rawson, K.A.; Girotto, S. Comprehension and Situation Awareness. In Handbook of Applied Cognition; Durso, F.T., Nickerson, R.S., Dumais, S.T., Lewandowsky, S., Perfect, T.J., Eds.; John Wiley \& Sons Inc.: New York, NY, USA, 2007; p. 163.

39. Wickens, C.D.; Hollands, J.G.; Banbury, S.; Parasuraman, R. Engineering Psychology E Human Performance; Psychology Press: London, UK, 2015.

40. Endsley, M.R.; Bolte, B.; Jones, D.G. Designing for Situation Awareness; CRC Press: Boca Raton, FL, USA, 2003. 
41. Robson, L.S.; Stephenson, C.M.; Schulte, P.A.; Amick, B.C.I.; Irvin, E.L.; Eggerth, D.E.; Chan, S.; Bielecky, A.R.; Wang, A.M.; Heidotting, T.L.; et al. A systematic review of the effectiveness of occupational health and safety training. Scand. J. Work Environ. Health 2011, 38, 193-208. [CrossRef] [PubMed]

42. Nelson, A.; Baptiste, A.S. Evidence-Based Practices for Safe Patient Handling and Movement. Clin. Rev. Bone Miner. Metab. 2006, 4, 55-69. [CrossRef]

43. Bell, J.L.; Grushecky, S.T. Evaluating the effectiveness of a logger safety training program. J. Saf. Res. 2006, 37, 53-61. [CrossRef] [PubMed]

44. Helmkamp, J.C.; Bell, J.L.; Lundstrom, W.J.; Ramprasad, J.; Haque, A. Assessing safety awareness and knowledge and behavioral change among West Virginia loggers. Inj. Prev. 2004, 10, 233-238. [CrossRef] [PubMed]

45. Mujuru, P.; Helmkamp, J.C.; Mutambudzi, M.; Hu, W.; Bell, J.L. Evaluating the impact of an intervention to reduce injuries among loggers in West Virginia, 1999-2007. J. Agric. Saf. Health 2009, 15, 75-88. [CrossRef] [PubMed]

46. Teizer, J.; Allread, B.S.; Fullerton, C.E.; Hinze, J. Autonomous pro-active real-time construction worker and equipment operator proximity safety alert system. Autom. Constr. 2010, 19, 630-640. [CrossRef]

47. Ahn, S.Y.; Jeon, Y.W.; Yun, J.M.; Kang, P.; Ko, J.H.; Park, P. Development of a forward visibility assessment tool based on visibility angle. Int. J. Autom. Technol. 2015, 16, 1051-1055. [CrossRef]

48. Reed, M.P.; Manary, M.A.; Flannagan, C.A.; Schneider, L.W. Effects of vehicle interior geometry and anthropometric variables on automobile driving posture. Hum. Factors 2000, 42, 541-552. [CrossRef] [PubMed]

49. Vogt, C.; Mergl, C.; Bubb, H. Interior layout design of passenger vehicles with RAMSIS. Hum. Factors Ergon. Manuf. Serv. Ind. 2005, 15, 197-212. [CrossRef]

50. Di Gironimo, G.; Monacelli, G.; Patalano, S. A Design Methodology for Maintainability of Automotive Components in Virtual Environment. In Proceedings of the 8th International Design Conference (DESIGN 2004), Dubrovnik, Croatia, 16-19 May 2004; pp. 1-12.

51. Reed, M.P.; Ebert, S.M.; Hoffman, S.G. Modeling Foot Trajectories for Heavy Truck Ingress Simulation; CRC Press: Miami, FL, USA, 2010.

52. Choi, N.-C.; Lee, S. Discomfort Evaluation of Truck Ingress/Egress Motions Based on Biomechanical Analysis. Sensors 2015, 15, 13568-13590. [CrossRef] [PubMed]

53. Teizer, J. Wearable, wireless identification sensing platform: Self-Monitoring Alert and Reporting Technology for Hazard Avoidance and Training (SmartHat). J. Inf. Technol. Constr. 2015, 20, 295-312. 